\title{
Optimal DG Placement using Multi Objective Firefly Optimization with Eco-Technical Considerations
}

\author{
Abhishek Kumar ${ }^{1}$, Dr.Naresh Kumar ${ }^{2}$ \\ M.Tech Scholar, Electrical Engineering, DCRUST, Murthal, Haryana, India ${ }^{1}$ \\ Assistant Professor, Electrical Engineering, DCRUST, Murthal, Haryana, India ${ }^{2}$
}

\begin{abstract}
The first contribution of this paper is to present three alternative analytical expressions to identify the location, size and power factor of a single DG unit with a goal of minimizing power losses. These expressions are easily adapted to accommodate different types of renewable DG units for minimizing energy losses by considering the time-varying demand and different operating conditions of DG units. Second objective is to minimize the cost of plantation of renewable energy source at the buses with high losses. This cost also must be minimized in coordination with losses minimization. A meta heuristic algorithm, firefly optimization is used for this purpose. Results are compared with the other metaheuristic algorithm, widely used in literature, particle swarm optimization (PSO). Comparative results in form of losses and voltage profile improvement shows effectiveness of our algorithm.
\end{abstract}

Keywords: Distributed Generation, Firefly Optimization, PSO

\section{INTRODUCTION}

Distributed Generation plays a vital role in the electric power system due to increased availability of small capacity generation technologies [1]. DG installations require special studies and attention to help maintaining system reliability and performance. Optimal allocation of DG effectively reduces the operational cost and increases the reliability and quality of power supply and also cuts down the power and energy losses. DG has significant impact on the voltage profile of the system. Voltage profile is defined as the change in the voltage of the system as the load changes. With the increased loading and exploitation of the existing power structure, the probability of occurrence of voltage collapse are significantly greater than before and the identification of the nodes which are prone to the voltage fluctuations have attracted more attention for the transmission as well as the distribution systems. For operating a power system in a safe and secure manner, all unsecure operating states can be identified and DG placement can be done, in order to enhance the voltage stability margin [2]. Many researchers have introduced different DG placement algorithms using analytic or heuristic approaches. Only a few works have been concentrated on optimizing the effect DG in voltage stability improvement. A method of finding a continuum of power flow solutions starting at some base load and leading to the steady state voltage stability limit of the system was presented in [3]. A method for DG placement in radial distribution networks which uses CPF to identify the most sensitive bus to voltage collapse has been applied in [4]. Voltage stability analysis of large power systems using a modal analysis technique was proposed in [5], which gives the idea about the proximity to voltage collapse. In [6] optimal DG allocation has been identified which is based on the modal analysis and compared the effectiveness of the method to the CPF method. The determination of maximum loading is one of the most important problems in voltage-stability analysis that cannot be calculated directly by modal analysis.
A method combining CPF and Modal analysis was proposed in [7] for the optimal DG placement considering voltage stability enhancement. Application of different optimization techniques in DG placement problem were also discussed in literature. Optimization techniques applied to DG placement and sizing, are genetic algorithm [8], tabu search [9], analytical and numerical based methods [10-30]. In this paper, a DG placement problem is solved by using firefly Optimization and compared with particle swarm optimization (PSO) algorithm, based on Newton - Raphson power flow method, Continuation Power Flow and Modal Analysis, while the objective is to maximize the Voltage Stability Margin and reduce the power losses. Case studies are carried out in an IEEE-14 Bus System using MATLAB.

\section{PROPOSED WORK}

To mitigate losses in the system extra renewable generators are installed on buses. If extra generators are installed on each bus in the system, it will definitely increase the cost and losses. So it is necessary to choose some potential buses at which generators can be placed. For this purpose sensitivity index is calculated in our work. It will arrange all buses in the decreasing order of power losses. Then as per the cost minimization and losses minimization, a number of buses which art at top of the list can be chosen and generators will be installed only on that.

The sensitivity factor of real power loss with respect to real power injection is obtained by differentiating exact loss formula with respect to real power injection at bus Pi which is given by:

$$
\alpha_{i}=\frac{\partial P_{i}}{\partial P_{j}}=2 \sum_{j=1}^{N}\left[\alpha_{i, j}\left(P_{j}\right)\right]-\beta_{i, j}\left(Q_{j}\right)
$$

Sensitivity factors are evaluated at each bus, firstly by using the values obtained at base case load flows. 
The buses are ranked in descending order of the values of This criterion represents efficiency of DG collection sensitivity factors to form a priority list [11].The total system [3].

power loss against injected power is a parabolic function Combining the objective functions described in above two and at minimum of losses, the rate of change of real power sections, we minimize the losses and cost too. The final loss with respect to real power injection becomes zero.

$$
\alpha_{i}=\frac{\partial P_{i}}{\partial P_{j}}=2 \sum_{j=1}^{N}\left[\alpha_{i, j}\left(P_{j}\right)\right]-\beta_{i, j}\left(Q_{j}\right)=0
$$

which follows that,

$$
P_{i}=\frac{\partial P_{i}}{\partial P_{j}}=\frac{1}{\alpha_{i i}}\left[\beta_{i, i}\left(Q_{i}\right)+\sum_{j=1}^{N}\left[\alpha_{i, j}\left(P_{j}\right)\right]-\beta_{i, j}\left(Q_{j}\right)\right]
$$

After locating potential buses with highest losses DG is installed over them. The capacity of DG is tuned by firefly using objective functions defined below.

(a) Technical constraint of Objective function

The objective of the optimal size and location of DG problem to minimize the total power loss and voltage profile can be expressed as:

Minimize $P_{L}=\sum_{i=1}^{N} \sum_{j=1}^{N}\left[\begin{array}{c}{\left[\alpha_{i, j}\left(P_{i} P_{j}+Q_{i} Q_{j}\right)\right]+} \\ \beta_{i, j}\left(Q_{i} P_{j}-P_{i} Q_{j}\right)\end{array}\right.$

where

$$
\begin{gathered}
\alpha_{i, j}=\frac{r_{i, j}}{V_{i} V_{j}} \cos \left(\delta_{i}-\delta_{j}\right) \\
\beta_{i, j}=\frac{r_{i, j}}{V_{i} V_{j}} \sin \left(\delta_{i}-\delta_{j}\right) \\
z_{i, j}=r_{i, j}+j x_{i, j}
\end{gathered}
$$

where

$z_{i, j}$ is the impedance of the line between bus $i$ and bus $\mathrm{j}$;

$r_{i, j}$ is the resistance of the line between bus $i$ and bus $j$;

$x_{i, j}$ is the reactance of the line between bus $\mathrm{i}$ and bus $\mathrm{j}$ is the voltage magnitude at bus $i$ is the voltage magnitude at bus j

(b) Economical Constraint of Objective function

With technical description of objective function the cost incurred in the installation is also considered in the form of economical constraint. The objective function for it is given as:

$$
\text { minimize } C=\frac{\sum_{n=1}^{N} \sum_{j=1}^{J} A_{D G}^{n j} \cdot T^{n j}}{\sum_{n=1}^{N} \sum_{j=1}^{J}\left(C_{D G}^{n j} \cdot P_{D G}^{n j} \cdot k_{c o n n}^{n j}\right)} \Delta A_{\text {coll }}
$$

Where:

$N$ - Total number of power grid nodes, where DG source can be placed;

$A_{D G}^{n j}$ - Amount of electricity produced by DG source of type $j$ placed at node $n$ (during the specific calculation period);

$T^{n j}$ - Local tariff for electricity produced by DG source of type $j$ placed at node $n$;

$C_{D G}^{n j}-$ Specific cost of DG source of type $j$ placed at node $n$

$P_{D G}^{n j}$ - rated power of DG source of type $j$ placed at node $n$; $k_{\text {conn }}^{n j}$ - Connection factor to the power grid, which characterizes price for connection of DG source of type $j$ placed at node $n$. As a rule, this factor depends on rated power of DG source and nominal voltage of the power grid;

$\Delta A_{\text {coll }}$ - characterizes reduction of electricity losses in the internal power grid of the power plant with DG units (loss of profit). objective function in our case is

$$
\text { objf }=\text { minimise }\left(P_{L}+\frac{1}{C}\right)
$$

The above objective function is minimized using firefly optimization. A pseudo code for firefly optimization is shown in below table.

$$
\begin{aligned}
& \text { Begin } \\
& \text { 1) } \\
& f(\mathbf{x}), \quad \mathbf{x}=\left(x_{1}, x_{2}, \ldots, x_{d}\right)
\end{aligned}
$$

2) Generate an initial population of fireflies $\mathbf{x}_{i} \quad(i=1,2, \ldots, n)$.

3) Formulate light intensity $I$ so that it is associated with $f(\mathbf{x})$

(for example, for maximization problems, $I \propto f(\mathbf{x})$ or simply $I=f(\mathbf{x})$;

4) Define absorption coefficient $\gamma$

While ( $\mathrm{t}<$ MaxGeneration)

for $\mathrm{i}=1: \mathrm{n}$ (all $\mathrm{n}$ fireflies)

for $\mathrm{j}=1: \mathrm{n}$ ( $\mathrm{n}$ fireflies)

if $\left(I_{j}>I_{i}\right)$,

move firefly i towards j;

end if

Vary attractiveness with distance $r$ via $\exp (-\gamma r)$

Evaluate new solutions and update light intensity

end for $j$

end for $\mathrm{i}$

Rank fireflies and find the current best; end while

Post-processing the results and visualization;

End

\section{RESULTS}

The IEEE 14 bus system is sued as our test case which is shown in appendix. It has five generators attached to different buses. We have used firefly optimization as discussed to optimize the capacity of wind DG's so that losses and cost reduces. it has been kept in continuous checking that no single bus gets same capacity DG. As discussed in previous section, combination of technical and economical constraints is used to minimize the fitness function by firefly optimization.

A fitness function plot for only technical and combination of both is shown in figure 2 below.

We have compared our work with PSO. The optimal sizing of DG placed at potential buses is given in table 1 below for both cases. 


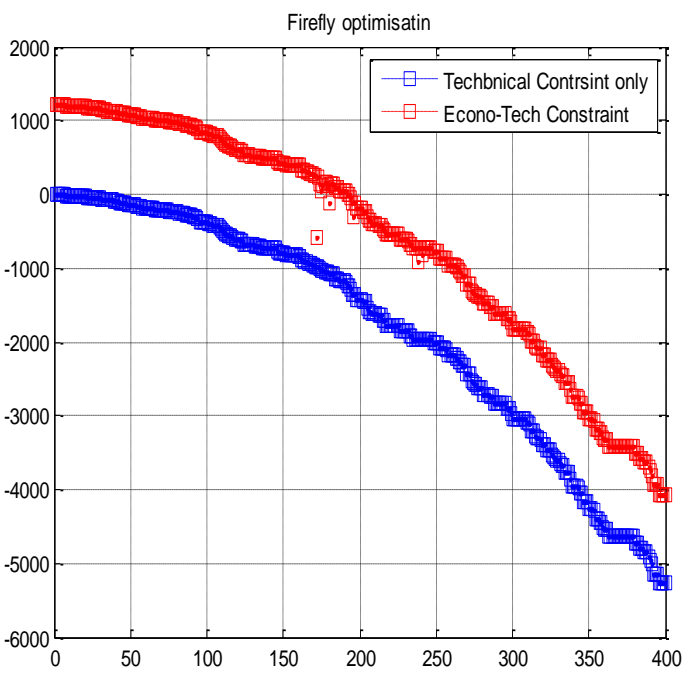

Figure 2: Minimization of fitness function by firefly optimization

TABLE 1: DG placed at potential buses

\begin{tabular}{|l|l|l|l|l|}
\hline $\begin{array}{l}\text { Potential } \\
\text { Bus }\end{array}$ & $\begin{array}{l}\text { DG } \\
\text { capacity } \\
\text { by } \\
\text { technical } \\
\text { constraint } \\
\text { only in } \\
\text { firefly }\end{array}$ & $\begin{array}{l}\text { DG } \\
\text { capacity } \\
\text { by Eco- } \\
\text { technical } \\
\text { constraint } \\
\text { only in } \\
\text { firefly }\end{array}$ & $\begin{array}{l}\text { DG } \\
\text { capacity } \\
\text { by } \\
\text { technical } \\
\text { constraint } \\
\text { only in } \\
\text { PSO }\end{array}$ & $\begin{array}{l}\text { DG } \\
\text { capacity } \\
\text { by Eco- } \\
\text { technical } \\
\text { constraint } \\
\text { only in } \\
\text { firefly }\end{array}$ \\
\hline 1 & 82.939 & 48.588 & 0.307 & 0.307 \\
\hline 8 & 95.824 & 42.740 & 2.687 & 2.687 \\
\hline 9 & 94.251 & 50.7808 & 0.6726 & 0.6726 \\
\hline 10 & 82.0903 & 48.698 & 5.985 & 5.9852 \\
\hline
\end{tabular}

After placing theses much of generators the line losses reduce. These line losses are compared in figure 3 for clear demonstration of efficiency of proposed work. The figure shows that line losses decrease with firefly optimization with eco-technical constraint more than only technical constraint and if PSO is used then losses follows the old line losses. It proves that considering cost too in the objective function, reduces the line losses as well as cost. Although in some branches, line losses by proposed formulation is higher, yet overall losses are least in our case with eco-technical case as shown in figure 4.

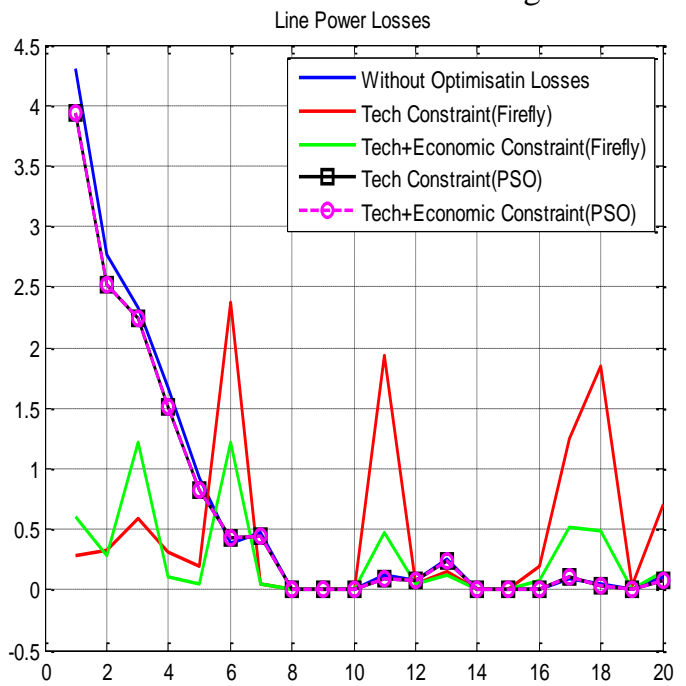

Figure 3: Line losses comparison of firefly and PSO with technical and eco-technical constraints

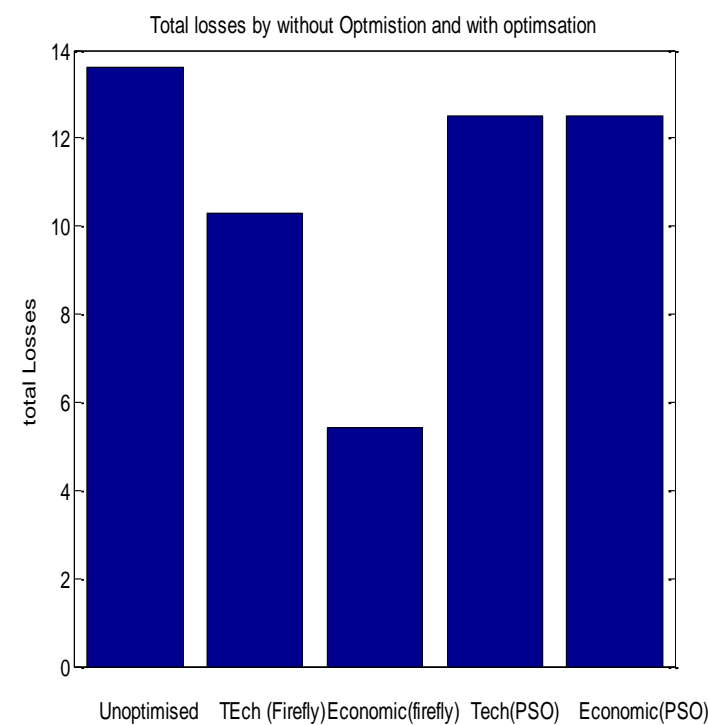

Figure 4: Total losses in all considered cases

The voltage profile at each bus should also improve after DG placement. The capacity of DG should be such that voltage profile of buses increases. A figure 5 shows the comparison of voltage profile for all cases. It clearly shows that DG capacity by proposed eco-technical constraint, improves voltage profile more than others.

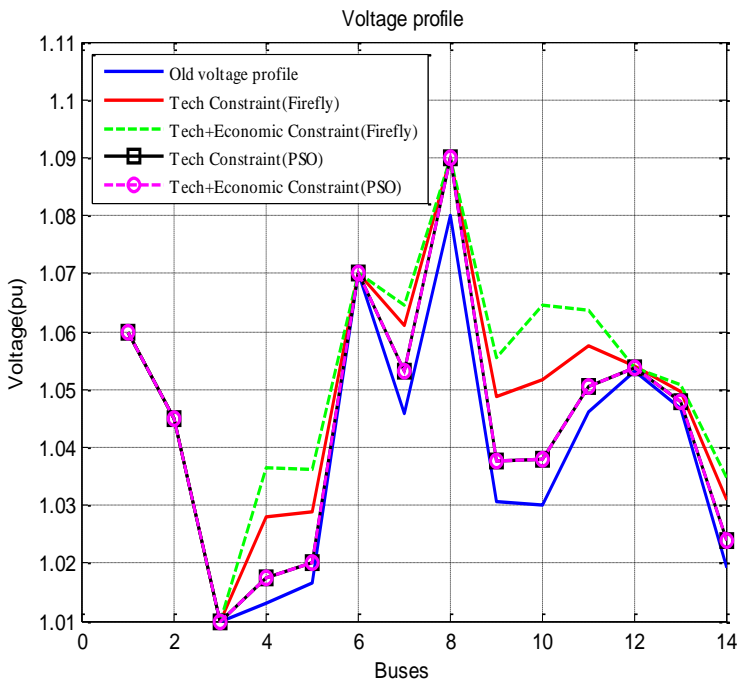

Figure 5: Voltage Profile at each bus for firefly optimized case and PSO optimized case

\section{CONCLUSION}

Increasing interest in the deployment of renewable DG worldwide, especially intermittent resources (i.e., wind), together with demand variations is forcing modifications to the planning and operations of renewable DG units. The concluding points of the this work are as:

Technical as well as economical objective functions are considered so that cost of installation and power losses are reduced. Loss sensitivity method decreases the requirement to put renewable generators on all buses. It gives the exact buses at which losses are highest and DG can be placed on those buses. Optimal sizing method is used here to determine the optimal size of wind turbines placed on the high loss buses. Firefly optimization serves the purpose here and results are compared with particle 
swarm optimization. Results comparison is done in the form of line losses and improved voltage profile. It has been shown that firefly gives better improved results than widely used PSO in literature and losses in considering multi objective function are minimized more.

\section{REFERENCES}

[1] R. E. Brown, Electric Power Distribution Reliability, CRC Press, 2008

[2] Marko Vukobratovic et.al "Optimal Distributed Generation Placement in Distribution Network” ENERGYCON 2014 • May 13$16,2014$.

[3] L.M. Lukianenko et.al,"Determination of the Optimal Placement and Capacity of Distributed Generation" ,IEEE International Conference on Intelligent Energy and Power Systems, 2014.

[4] Ebrahim Babaei et.al, "Optimal Placement of DG Units Considering Power Losses Minimization and Voltage Stability Enhancement in Power System", International Journal of Automation and Control Engineering Volume 3 Issue 1, February 2014.

[5] S.P.Rajaram et.al,"Optimal Placement of Distributed Generation for Voltage Stability Improvement and Loss Reduction in Distribution Network", International Journal of Innovative Research in Science, Engineering and Technology, Volume 3, Special Issue 3, March 2014.

[6] H. L. Willis, Distributed Power Generation: Planning and Evaluation, CRC Press, 2000.

[7] Deepak Pandey et.al, “ Optimal Placement \& Sizing Of Distributed Generation (DG) to Minimize Active Power Loss Using Particle Swarm Optimization", International journal of scientific \& technology research volume 3, issue 7, july 2014.

[8] T. Ackermann, G. Andersson and L. Söder, "Distributed generation: A definition," Electr. Power Syst. Res, vol. 57, no.3, pp. 195-204, 2001.

9] Rashmi Priya et.al, "Optimal Location and Sizing of Generator in Distributed Generation System" International Journal of Innovative Research in Electrical, Electronics, Instrumentation And Control Engineering Vol. 2, Issue 3, March 2014.

[10] Maruthi Prasanna et.al, "A new simplified approach for optimum allocation of a distributed generation unit in the distribution network for voltage improvement and loss minimization",International journal of electrical engineering \& technology, volume 4, issue 2, march, 2013.

[11] M. Padma Lalita et.al, "Siting \& Sizing of Dg for Power Loss \& Thd Reduction, Voltage Improvement Using Pso \& Sensitivity Analysis", International Journal of Engineering Research and Development, Volume 9, Issue 6 ,December 2013.

[12] Amany M. El-Zonkoly, "Optimal Placement of Multi DG Units Including Different Load Models Using PSO" Smart Grid and Renewable Energy, 2010.

[13] Athira Jayavarma, et.al, "Optimal Placement of Solar PV in Distribution System using Particle Swarm Optimization" International Journal of Advanced Research in Electrical, Electronics and Instrumentation Engineering, Vol. 2, Special Issue 1, December 2013.

[14] S.Ishwarya et.al, "ICGICT Allocation of DG for IEEE 33 Bus Systems" International Journal of Innovative Research in Computer and Communication Engineering,Vol.2, Special Issue 1, March 2014.

15] Subin Sunny et.al, "The Better Optimization Technique for the Placement of DG In Order To Reduce Overall Cost of Power System" International Journal of Engineering and Advanced Technology Volume-2, Issue-5, June 2013.

[16] M.Jegadeesan et.al, "Optimal Sizing and Placement of Distributed Generation in Radial Distribution Feeder Using Analytical Approach" International Journal of Innovative Research in Science, Engineering and Technology Volume 3, Special Issue 3, March 2014.

[17] Azah Mohamed et.al, "Optimal DG Placement and Sizing For Voltage Stability Improvement Using Backtracking Search Algorithm",International Conference on Artificial Intelligence, Energy and Manufacturing Engineering,June 9-10, 2014.

[18] A. Nourai, V. I. Kogan, and C. M. Schafer, "Load leveling reduces T\&D line losses," IEEE Trans. Power Del., vol. 23, no. 4, pp. 2168-2173, Oct. 2008
19] K. S. Verma et.al, "GA based Optimal Sizing \& Placement of Distributed Generation for Loss Minimization" World Academy of Science, Engineering and Technology Vol: 1 2007-11-28.

20] Adnan Anwar et.al, "Loss Reduction of Power Distribution Network Using Optimum Size and Location of Distributed Generation" Power and Energy Society General Meeting, IEEE, 2012.

[21] D.Rama Prabha et.al, "Determining the Optimal Location and Sizing of Distributed Generation Unit using Plant Growth Simulation Algorithm in a Distribution Network" WSEAS TRANSACTIONS on Power systems, Volume 13, 2014.

[22] P.Sobha Rani et.al, "optimal sizing of dg units using exact loss formula at optimal power factor" International Journal of Engineering Science and Technology, Vol. 4 No.09 September 2012

[23] Ram Singh et.al, "Optimal Placement of DG in Radial Distribution Network for Minimization of Losses" International Journal of Advanced Research in Electrical, Electronics and Instrumentation Engineering Vol. 1, Issue 2, August 2012.

[24] P. Siva Prasad et.al, "Optimal Distributed Generation Placement in Radial Distribution Systems Based on Combined Power Loss Sensitivity Approach" National Conference on Power Distribution, DSD-CPRI, Bangalore-February 6th \& 7th 2014

25] Sharmistha Sharma et.al, " A Load Flow based Approach for Optimum Allocation of Distributed Generation Units in the Distribution Network for Voltage Improvement and Loss Minimization" International Journal of Computer Applications Volume 50 - No.15, July 2012.

[26] Sarin Baby et.al, "Optimal DG Placement Considering Voltage Stability Enhancement Using PSO” International Conference on Control Communication and Computing, 2013.

[27] Navuri P Kumar et.al, "Optimal Planning of Distributed Generation for Improved Voltage Stability and Loss Reduction" International Journal of Computer Applications Volume 15- No.1, February 2011

[28] T. Wen Shan, M. Y. Hassan, H. A. Rahman, M. P. Abdullah, and F. Hussin, "Multidistributed generation planning using hybrid particle swarm optimization gravitational search algorithm including voltage rise issue," IET Gener. Transm. Distrib., vol. 7, no. 9, pp. 929-942, Sep. 2013.

[29] V. H. Méndez, J. Rivier, J. I. d. 1. Fuente, T. Gómez, J. Arceluz, J. Marín, and A. Madurga, "Impact of distributed generation on distribution investment deferral," Int. J. Elect. Power Energy Syst., vol. 28, no. 4, pp. 244-252, May 2006

[30] G. Celli, E. Ghiani, S. Mocci, and F. Pilo, "A multiobjective evolutionary algorithm for the sizing and siting of distributed generation," IEEE Trans. Power Syst., vol. 20, no. 2, pp. 750-757, May 2005. 